\title{
Systematicity theory meets Socratic scientific realism: the systematic quest for truth
}

\author{
Timothy D. Lyons \\ Indiana University-Purdue University Indianapolis
}

\begin{abstract}
Systematicity theory — developed and articulated by Paul Hoyningen-Huene — and scientific realism constitute separate encompassing and empirical accounts of the nature of science. Standard scientific realism asserts the axiological thesis that science seeks truth and the epistemological thesis that we can justifiably believe our successful theories at least approximate that aim. By contrast, questions pertaining to truth are left "outside" systematicity theory's "intended scope" (21); the scientific realism debate is "simply not" its "focus" (173). However, given the continued centrality of that debate in the general philosophy of science literature, and given that scientific realists also endeavor to provide an encompassing empirical account of science, I suggest that these two contemporary accounts have much to offer one another. Overlap for launching a discussion of their relations can be found in Nicholas Rescher's work. Following through on a hint from Rescher, I embrace a non-epistemic, purely axiological scientific realism — what I have called, Socratic scientific realism. And, bracketing the realist's epistemological thesis, I put forward the axiological tenet of scientific realism as a needed supplement to systematicity theory. There are two broad components to doing this. First, I seek to make clear that axiological realism and systematicity theory accord with one another. Toward that end, after addressing Hoyningen-Huene's concerns about axiological analysis, I articulate a refined axiological realist metahypothesis: it is, in short, that the end toward which scientific inquiry is directed is an increase in a specific subclass of true claims. I then identify a key feature of scientific inquiry, not generally flagged explicitly, that I take to stand as shared terrain for the two empirical meta-hypotheses. And I argue that this feature can be informatively accounted for by my axiological meta-hypothesis. The second broad
\end{abstract}

This is the author's manuscript of the article published in final edited form as:

Lyons, T. D. (2017). Systematicity theory meets Socratic scientific realism: the systematic quest for truth. Synthese. https://doi.org/10.1007/s11229-017-1561-2 
component goes beyond mere compatibility between the two positions: I argue that, in want of a systematic account of science, we are prompted to find an end toward which scientific inquiry is directed that is deeper than what systematicity theory offers. Specifically, I argue that my refined axiological realist meta-hypothesis is required to both explain and justify key dimensions of systematicity in science. To the quick question, what is it that the scientific enterprise is systematically doing? My quick answer is that it is systematically seeking to increase a particular subclass of true claims.

\section{Keywords}

Scientific realism; Systematicity theory; Theories of scientific inquiry; Aims of science; Axiological scientific realism; Scientific method; Theory choice; Explanatory virtues; Socratic scientific realism

\section{Systematicity theory and scientific realism}

Systematicity theory—developed and articulated by Paul Hoyningen-Huene (2014)—offers a thorough and rich account of the nature of science. The central thesis is the following: compared to instances where we have "some extra-scientific knowledge about the same subject matter" as we have scientific knowledge, the "scientific knowledge will exhibit a greater degree of systematicity" (24). It is "systematicity that sets science apart from everyday knowledge" (165). This systematicity is spread across what Hoyningen-Huene identifies as "nine dimensions (or areas or aspects) of science" (27): description, explanation, predictions, the defense of knowledge claims, critical discourse, epistemic connectedness, the ideal of completeness, the generation of new knowledge, and the representation of knowledge. Although these dimensions “overlap" (36, 120, 141), all are “descendants of" (28)—and each is such as to "highlight a special aspect of" (36) — "the abstract concept of systematicity" (28). And "when comparing two areas with respect to their degrees of systematicity, we are referring to an overall systematicity aggregating all nine dimensions" (169).

Hoyningen-Huene sees a long history before him that hints at, but does not follow through on, his project. The "older positions are special cases" (148), "restricted versions of the idea of systematicity in nine 
dimensions" (150), systematicity being "the wider concept" than the "methodicity" emphasized by his predecessors (149). Notably, Hoyningen-Huene sees Nicholas Rescher as most closely approximating his own theory, as "the only philosopher who extensively considered systematicity and its relationship with science in the last one hundred years" (18). Nonetheless, and tellingly, Hoyningen-Huene points to a fundamental difference, where again systematicity remains "the wider concept" (174). While, for Rescher, "systematicity" is "derived from the noun 'system'," Hoyningen-Huene's "systematicity" derives from the adjective "systematic" (174). This is helpful in both clarifying Hoyningen-Huene's project and revealing the need for greater clarity.

Because "science" is commonly taken to reference a corpus of ideas, and given Hoyningen-Huene's ubiquitous talk of "scientific knowledge," we may well expect the adjective "systematic" to modify only that corpus. This would accord with taking his dimensions as "dimensions of systematicity of knowledge" and especially with what he calls his "one and only one general thesis": "that scientific knowledge is more systematic than other forms of knowledge" (xi). That the ideas in science are more securely embedded in a system than are other ideas is an anticipated consequence of his central claim, so part of it. However, his explicit shift from Rescher's term prompts us to resist taking the adjective "systematic" to modify only a corpus of ideas, as asserting merely that the content of science resides in a theoretical system. The term "science" can also denote an enterprise. Now we're on track. In accord with Hoyningen-Huene's discussion of science as a "human enterprise" (e.g. 89) and somewhat boldly discarding his dominant treatment of "scientific knowledge" as systematic, I propose that what he is most fundamentally claiming to be systematic is, not the collection of products of the scientific enterprise, but that enterprise itself. More carefully, since an enterprise involves doing something, the core claim is that the scientific enterprise involves doing something systematically.

What is it that is done systematically? Given, again, his contrast against Rescher, the answer is not merely building a system. Here we might be tempted to assume the adjective "systematic" or "done systematically" modifies each of the "dimensions" of science that Hoyningen-Huene articulates: 
describing, predicting, explaining .... I don't think this is incorrect. And although Hoyningen-Huene might not state the following explicitly, I think it is a non-contentious step to say that all such activities are done in service of - or even stand as instances of - a more general activity: inquiring. HoyningenHuene is offering what he sees as only a tenuous unity between the various dimensions (28) and domains of science $(29,169,209)$. However, I suggest that discarding "knowledge" and invoking the term "inquiry" explicitly affords a stronger grasp of the unity on offer: the scientific enterprise is marked by systematic inquiry. ${ }^{1}$ Moreover, given the empirical emphasis of Hoyningen-Huene's theory, we can affirm that what he is offering is an empirical meta-hypothesis, one about the nature of scientific inquiry. Although we've gone beyond his own phrasing, I take this formulation to be both non-contentious and informative.

I emphasize this formulation also because it facilitates an attempt to relate systematicity theory to other such empirical meta-hypotheses. More specifically, a general objective in the present paper is to connect systematicity theory to topics arising in the scientific realism debate. At issue in that debate are two central questions, one axiological, the other epistemological. The questions are, respectively, "What is the aim of science?" and "What can we justifiably believe about empirically successful scientific theories?" Standard scientific realism replies that science seeks truth and we can justifiably believe that our successful theories achieve or approximate that aim. The first posit here can be seen as the axiological posit, which itself can be seen as an empirical meta-hypothesis about the nature of scientific inquiry. The second is the epistemic postulate. And that which the second posit claims we can justifiably believe is another purportedly empirical meta-hypothesis, a basic version being "our successful theories are (at least approximately) true." Given the continued centrality of the scientific realism debate in the general philosophy of science literature, and given that, as with systematicity theory, scientific realism endeavors to provide an encompassing empirical account of science, two important questions loom large: just how do these two general philosophies of science interrelate? and how might they supplement one 
another? Explicitly recognizing that systematicity theory is an empirical meta-hypothesis about the nature of scientific inquiry, we now have a framework for addressing these questions.

\subsection{Systematicity theory and epistemic scientific realism}

Mindful of that framework, however, further clarifications are required. The first pertains again to Hoyningen-Huene's liberal use of "knowledge.” In fact, from any number of instances of his primary thesis, one could get the impression that systematicity theory is appended to, or even presupposes, epistemic scientific realism. Addressing the question of "what aspects of science" he is focusing on, he answers, "the epistemic aspects of science, i.e. science in the sense of scientific knowledge" (9). As hinted at above, a basic and pre-reflective variant of epistemic scientific realism says that we can be justified in believing that our successful scientific theories are true. On the grounds that to believe that $\mathrm{T}$ is true is simply to believe T, and accepting both that we are so justified and that our successful theories are in fact true, our belief in the theories themselves would constitute knowledge by the traditional (albeit incomplete) definition of "knowledge" as justified true belief. For various reasons, this "pre-reflective" version of scientific realism, despite its continued presence in the literature, is patently untenable - due to, for one example, the clash between our best theories, quantum field theory and general relativity (see my 2015). The far more sophisticated contemporary versions are such that what they claim we can justifiably believe is, not the content of scientific theories themselves, but an empirical meta-hypothesis about them that is no longer reducible to theories, a dominant version being, "those constituents that are genuinely deployed in the derivation of successful novel predictions are at least approximately true." Though we're now a step removed from believing scientific theories per se, provided that meta-hypothesis is true, and provided we are justified in believing it, then, by the traditional definition, that meta-hypothesis would be the object of our knowledge. (Put another way, I dare say that without it the contemporary realist has no such object). And it would be easy to read some of Hoyningen-Huene's key phrases as committing him to either the first, or more implicitly, the second version of epistemic scientific realism. 
However, as Hoyningen-Huene makes explicit, his use of "knowledge" is not to be understood by the traditional definition: that term pertains not to, say, justified true belief, but to a corpus of ideas "wellestablished, widely held in the relevant community, not regarded as tentative or falsified" (21). ${ }^{2}$ Beyond that crucial terminological clarification, we can note that Hoyningen-Huene also explicitly denies embracing epistemic realism: though he is concerned with "how the sciences function" (173) as compared to "everyday thought," he is not, for instance, asking whether science is more successful than other areas at "reaching the truth" (173). He seeks to avoid any presupposition "that what counts as scientific knowledge today is literally true" (21). ${ }^{3}$ That epistemic question is meant to be "open" and left "outside the intended scope" of his discussion (21). Explicitly, the scientific realism debate is "simply not the focus of systematicity" (173). Going beyond Hoyningen-Huene's text on systematicity, other texts of his strongly suggest that he rejects epistemic realism (e.g. 2009).

In fact, although old forms of epistemic realism pertain to science in general, those forms have now come to be treated as untenable. And it is important to at least indicate here why any attempt at embracing contemporary epistemic realism will not help in one's attempt to account for science in general. Given the last few decades of, for instance, historical research taking place in the scientific realism debate, epistemic realism has come to restrict itself to an extraordinary degree. As opposed to the basic meta-hypotheses above, realists have found themselves forced to modify the meta-hypothesis they claim we can justifiably believe. They've had to narrow their commitments to such an extent that they commit to little of what we broadly call science. For instance, among all the posits accepted by scientists based on explanatory success and novel success, most realists commit to only those that are deployed in the derivation of novel predictive successes, as noted above. However, even this restriction does not suffice historically (see e.g. Lyons 2006), and in response realists reduce their commitment even further. (See Vickers (2013, p. 202) responding to Lyons (2006) specifically.) That is, even from among those constituents that are deployed toward successful novel predictions, the realist is forced to restrict her commitment to only the "smallest part" of the constituent, "only the content of H necessary to ensure that the derivation" to the novel 
prediction "goes through" (my italics) (Vickers 2013, p. 202). The natural question is whether this leaves any commitment beyond some minimal and merely empirical statement that entails the prediction itself. Rather than engaging on that natural question here, suffice it to say that forms of contemporary epistemic realism that invoke so strict a set of believability criteria exclude most of the content of accepted science. In that case, those forms of epistemic realism are incapable of standing on their own as an account of the value of scientific theories, or the nature of scientific inquiry, in general.

\subsection{Systematicity theory and axiological scientific realism: preliminaries}

The problems noted here, however, pertain only to the epistemic posit of scientific realism. And admittedly that has been the focus in the literature, on both sides: contemporary anti-realists who challenge the epistemological tenet take their challenges, at least implicitly, as sufficient condemnation of the axiological tenet; and despite the centrality of their own axiological tenet, most realists have focused only on defending the epistemic posit. An unfortunate consequence of this focus on the epistemic posit has been that the project of carefully articulating a realist (or for that matter, an anti-realist) axiology, has been largely neglected. [Likewise, but more generally, Hoyningen-Huene notes that axiology "is seldom systematically treated in the current philosophy of science" (242)]. Although I have argued in a series of papers that the epistemological tenet of scientific realism faces serious problems (e.g. Lyons 2002, 2003, 2006, 2009, 2014, 2015), I resist the temptation to assume the axiological tenet collapses under the epistemic wake. And in evaluating empirical meta-hypotheses about the nature of scientific inquiry, I suggest, it is the realist's axiological tenet to which systematicity theory can be most fruitfully related.

In fact, Rescher's work provides overlap for launching my discussion of their relation. Separate from discussing scientific systems, Rescher also at least suggests retaining the idea that science seeks truth while allowing that we may not justifiably believe it has been achieved (1982). Although I've argued elsewhere that Rescher does not follow through on this proposal (2011), my own proposal has as its foundation, as indicated, the articulation and application of the axiological tenet of scientific realism. That is, in want of developing a non-epistemic, purely axiological scientific realism, a truth based conception 
of inquiry that does not depend on epistemic scientific realism—what I've elsewhere (2015) called Socratic scientific realism - I offer a refined version of the empirical meta-hypothesis that science seeks truth, including truth about unobservables. Like systematicity theory, this refined axiological realism is meant to be an account of inquiry that incorporates "many of the valuable insights developed in the history of philosophy about the nature of science" (150). While I join Hoyningen-Huene in his project of bracketing off the epistemic tenet, I invite him to explicitly embrace a refined realist axiology. Bracketing the one and embracing the other, this is ultimately, then, an invitation to conjoin Socratic scientific realism to systematicity theory.

My invitation has two broad components. The first broad component: despite the fact that HoyningenHuene is resisting discussions of axiology and an appeal to truth even as an aim of science, I will endeavor to make clear that axiological realism accords well with systematicity theory. Toward that end, in addition to addressing in Sect. 2 Hoyningen-Huene's concerns about axiological analysis, I will articulate an axiological realist meta-hypothesis in Sect. 3. In Sect. 4, I will identify a feature of scientific inquiry not generally flagged explicitly — the quest to increase what I will call a system's degree of implication - that I take to stand as shared terrain for the two meta-hypotheses. And I will argue that my axiological realist meta-hypothesis explains and justifies this feature of scientific inquiry. The second broad component of my invitation goes beyond mere compatibility between the two positions: Although hinted at in Sect. 4, I will argue explicitly in Sect. 5 that, in want of a systematic account of science, my axiological realist meta-hypothesis provides a necessary supplement to systematicity theory. To give some indication of this in advance, consider the activities of systematically engaging in "institutionalized critical discourse" (109) and "organized skepticism" (110); or the activity of systematically importing contributions from one area to another; or that of systematically increasing the range of available databy, say, "building ever larger accelerators" and attaining "higher collision energies" (137)—and systematically using those data to test (11) scientific systems. I will argue that-along with increasing a system's degree of implication - these activities must be understood as being directed toward an end that 
is deeper than, say, merely an attempt to systematically inquire (let alone, to just 'be systematic'). I will contend that the axiological realist meta-hypothesis that I articulate in Sect. 3 is required to both explain and justify these and other key dimensions of systematicity in science. To the quick question, what is it that the scientific enterprise is systematically doing, in the course of systematically predicting, explaining, etc.? My quick answer — on behalf of Socratic scientific realism—will be that it is systematically seeking to increase a particular subclass of true claims.

\section{Systematicity theory as an axiological meta-hypothesis}

Engaging systematicity theory with the realism debate over axiology prompts us to ask whether the systematic inquiry that characterizes the scientific enterprise has an aim; that is, whether it is directed toward an end that can explain and/or justify its various means, a primary goal such that we can theorize about it in an empirically informative way. In accord with his setting aside the realism debate (21 and 173), Hoyningen-Huene expresses reluctance for explicitly engaging on axiological questions. Mindful of his concerns $(11 ; 116-118$, including the footnote on 242) and wanting to clear the way for further articulation of the issues below, I will try to briefly alleviate that reluctance.

Hoyningen-Huene's primary concern with the analysis and identification of goals is that such axiological considerations fail to distinguish science from non-science $(11,116-118)$. Although I agree, the expected failure of axiology as a demarcation criterion is not, by itself, a "failure" of axiology per se — of, say, putting forward an empirically informed characterization of the primary ends toward which an enterprise is directed. There is no sense in which an attempt to understand what is going on in science requires that it is only going on in science. The realist meta-hypothesis, for instance, does not require that all pseudosciences are not directed at truth (even if they are poorly directed) ${ }^{4}$ I also share a second concern of Hoyningen-Huene's, that insofar as axiologies of science are discussed they at least seem to be restricted to theories (242); and I agree that accounting for scientific activities other than theorizing is a key desideratum for any axiological thesis regarding science. ${ }^{5}$ He adds two further concerns: "Certainly, the answer"- to the question, "what precisely are the goals of science?"-_must be historically variable and 
is certainly also discipline dependent" (116). Admittedly, one might concur with Feyerabend's points, as Hoyningen-Huene appears to (168), that there is no single necessary and sufficient method of science, as described by, say, classic inductivists or falsificationists; and one would also have to accept the variability of some goals, simply because theories change historically and subject matter varies across disciplines. However, these concessions do nothing to imply that there is no end toward which the various methods of empirical inquiry are directed and to which various other (sub-)goals relate.

Hoyningen-Huene at least hints at the idea that describing the goals of science might be "impossible" (116). However, first, I suggest theorizing in an empirically informative manner about the ends toward which human inquiry directs itself is no less possible than, say, theorizing - from what our theories tell us is both spatially and temporally an infinitesimal and unusual speck-about the first micro-seconds, or the most fundamental constituents or processes, of a, say, 13.8 billion-year-old universe. Second, beyond the fact that Hoyningen-Huene has not shown that his account of science can stand while (somehow) eliminating even implicit appeal to goals, there are elements of systematicity theory that are clearly axiological. Not only are his discussions often axiologically informative, the dimensions of systematicity themselves are often properly treated as goals. In fact, Hoyningen-Huene unflinchingly makes assertions about goals, which are presumably supported — or are at least capable of being addressed — empirically $(29,49,110,127,133) .{ }^{6}$ He also discusses the importance of connecting methods or subgoals to a more primary goal (109). ${ }^{7}$ And he appears to take the possibility of primary goals seriously. For instance, he allows, with Heidegger, that "science does not think" (qtd. 190), but says, nonetheless, "one should reflect upon what science is up to" (190), and discusses the scientific "goal" of "explor[ing] the world ...by being more systematic" (190). ${ }^{8}$ Finally, in accord with his apparent axiological confidence toward which I'm now pointing — rather than his explicit methodological doubts about axiology — he even suggests what I consider to be a way to understand posits regarding the goals of science: noting its "wide currency" he recognizes that "talk of cognitive values that hold in scientific communities" does not require construing science as "an acting subject with intentions" (125); rather the relevant assertions are, what I would call, 
empirical meta-hypotheses about what is valued in science. Since a value becomes "operative by influencing the decisions," when we theorize about what is "positively valued" (126) by the scientific enterprise, the relevant phenomena are "theory decisions" (125). And those phenomena are, after all, what an axiological meta-hypothesis tries to explain (and I will argue, justify). Although I have not offered here an exhaustive defense of the axiological project, if there is anything beyond the problems raised and addressed here, it is unclear just what, beyond the desire for a demarcation criterion, was "the ultimate push away from the idea that 'goals of science' could do some work for systematicity theory" (242, footnote to 118). In any case, I've now at least indicated my grounds for resisting that push.

Given that Hoyningen-Huene does, and possibly must, engage with respect to goals, we are prompted to inquire whether systematicity is the overarching goal of scientific inquiry. In response to that question, I postulate that, no, there is a deeper goal that drives systematic inquiry. In support of that postulate, we ask, what kind of answers are systematically sought in the course of scientific inquiry? Since HoyningenHuene unhesitatingly calls science and other domains of inquiry "knowledge-seeking enterprises" (37, 242), and since he explicitly says "science itself strives for" (125) and constitutes the "search for" (89) knowledge, we may expect that, when pressed, "knowledge" is his unequivocal answer to the question of what is systematically sought. ${ }^{9}$ However, what again becomes crucial is systematicity theory's dependence on his definition of that term: for Hoyningen-Huene, systematically seeking knowledge amounts to systematically generating a corpus of ideas that are or will come to be accepted. This sheds no light on the kind of answers, the kind of ideas, that are systematically sought for acceptance. Our question calls for an informative answer.

\section{A purely axiological, Socratic, scientific realism: the goal of scientific inquiry as an increase in experientially concretized truth}

Hoyningen-Huene suggests that there has been a dearth of discussion of axiology in philosophy of science (242). I fully concur with this. Going beyond it, because axiology is pivotal to the realist proposal, I take there to be a dire need for systematically refining the typical and largely neglected realist axiology. 
Mindful of that need, the specific empirical meta-hypothesis I will offer here-originally introduced independently of considerations of systematicity theory $(2005,2011)$-is that science seeks, not truth per se, but a specific subset of true claims. Later I will endeavor to show that the two relevant empirical metahypotheses - that of Socratic scientific realism and that of systematicity theory-are, to borrow Hoyningen-Huene's phrase, "mutually enlightening" with regard to the nature of scientific inquiry. And as noted, beyond that, I will later argue that the former is more foundational than the latter, that my refined axiological realist meta-hypothesis offers the explanatory and justificatory foundation that systematicity theory needs.

\subsection{The axiological realist meta-hypothesis}

Central to my axiological meta-hypothesis is the specification of a certain subclass of true statements, abbreviated as XT statements:

Those whose truth is experientially concretized — that is, true statements whose truth is made to deductively impact, is deductively pushed to and enters into, documented reports of specific experiences, hereafter 'DRSEs'.

Supplementing the familiar notion of truth preservation, the deductive pushing here is theorizing: adding, modifying, or replacing low or high level auxiliary hypotheses or even core theoretical components. And the deductive entering into is the forging of logical connections by way of mediating terms. The truth of a statement $\mathrm{S}$ is made, in the course of such theorizing, to deductively impact a DRSE.

Because XT statements are a subclass of true statements, false statements are excluded. Although XT statements are true, they are distinguished from other true statements in that they cannot be vacuous-as would be a tautology. Nor can they be altogether detached from a theoretical system — as would be, say, “Leibniz's monads exist," with respect to our current theory complexes. Moreover, crucially, XT statements cannot be such that their truth fails to deductively reach any DRSEs due to obstruction by false statements in the theoretical system. (In 3.2, I will illustrate attempts to remedy such obstructions.) The 
extent to which an XT statement is experientially concretized can be understood as the range of DRSEs on which its truth is made to have deductive impact. Beyond that, there are varying degrees to which an XT statement can be made experientially concretized, where the 'degree of experiential concretization' references the gradation to which an XT statement has specification toward, and is impacting on, DRSEs. (Following historical illustrations in 4.2 that will turn out to be relevant to this notion, I will explicitly return to this issue in 4.4)

Importantly, the experiential concretization of XT statements is non-epistemic: no claim is being made here that we can discern just which statements in a theoretical system are in fact XT statements. It is not the case, for instance, that an XT statement's impact on DRSEs informs us of the XT statement's truth. Nonetheless, one can sometimes discern when and roughly where we have a deficiency of XT statements. With one type of evident XT-deficiencies, type (a), it is evident that non-XT statements are present in the theory complex. With another type, (b), it is evident that we possess DRSEs that have no matching prediction statements. (I will illustrate XT-deficiencies further in 3.2.) In slightly more detail then, my axiological realist postulate is that, in the course of modifying its theoretical systems, science seeks to remedy such evident XT-deficiencies by increasing the number - and/or the extent, degree, or exactitude of the experiential concretization — of XT statements; to retain or increase the extent and degree of the experiential concretization of each individual XT statement; to retain non-vacuous and non-detached statements that are not replaced; and to avoid increasing the non-XT (and the non-concretization of XT) statements.

A modification of a theoretical system achieving these conditions constitutes an 'increase in experientially concretized truth' or an IncXT. My postulate is that system modifications in science constitute the endeavor to achieve such a state; or, we might say, that state is that end toward which scientific theorizing — be it at the deepest or, let's say, most surface level of a theoretical system — is directed. ${ }^{10}$ I've shown elsewhere (2005) that a set of ten syntactic desiderata are required or at least promoted by the endeavor to achieve this end. More specifically, I show that the actual achievement of an 
IncXT entails and hence requires the achievement of an increase in empirical accuracy and consistency, and an increase in, or at least the retention of, breadth of scope, testability, and three forms of simplicity. There I also show that the quest for an IncXT promotes, but does not require, a fourth form of simplicity, temporally novel predictions, and explanatory depth.

\subsection{Brief illustrations of attempts to experientially concretize truths}

To illustrate some of the basic but primary content of my axiological realist meta-hypothesis, it is helpful to (admittedly, hastily) consider well-known cases of theorizing at various levels of theoretical systems. Allow me to forewarn that this is obviously no attempt to provide a thoroughly accurate history nor to secure the truth of the meta-hypothesis. Also, setting aside epistemic realism as I am, we need to bracket the notion that a given theory is in fact true, and, in accord with this emphasis, a number of the examples I will use for my illustration are those that I've argued in other contexts are rendered false by present lights (2006, 2016b). The idea is, nonetheless, that we can understand the process of theorizing regarding auxiliaries (including those packed into theory-laden "observations", etc.,) as treating the core theoretical components as true and as attempts to experientially concretize those truths. In these examples, the core theoretical components will be Newton's posit of an instantaneous action-at-a-distance force and Einstein's field equation.

Very early on, the Newtonian system was taken to be faced with a type (a) evident XT-deficiency—an instance where it is evident that non-XT statements are present in the theory complex-regarding the Earth's shape. In fact, it appears that the data initially favored the consequence of Descartes's vortex theory that the earth was lemon-shaped (Hoare, 2005, 28). On the axiological realist view, the Newtonians treated this evident XT-deficiency, not as an indicator of the falsity of Newton's force posit, but as an indicator that its truth was not yet experientially concretized in DRSEs theorized to pertain to the shape of the earth. After the famed expedition, however, the data came to be taken to accord with Newton's oblate-shaped earth prediction. On the assumption that Newton's force posit is true (irrespective of the fact that it is no longer taken to be), the idea is that the data from this expedition 
(would have) marked an increase in the experiential concretization of its truth. Quite soon, the moon's behavior was seen to be out of accord with Newtonian predictions, standing as another evident XTdeficiency for the Newtonian system. The Imperial Academy of St. Petersburg offered a prize for solving that problem in particular, awarded to Clariaut in 1752 (see Main 1860, pp. 159-160). Clariaut modified the auxiliaries - replacing non-XT statements present in the Newtonian complex-so that a more thorough account of the sun's pull on the moon was included in the calculations. On the axiological realist view, this would again be a case of remedying an XT-deficiency, so that the (presumed) truth of Newton's force posit was experientially concretized in those previously problematic DRSEs regarding observations of the moon. Later, in response to type (a) XT-deficiencies pertaining to the behavior of Jupiter and Saturn, Laplace developed perturbation theory — that now well-known and very complex process by which one adjusts the auxiliary scaffolding — to remedy the relevant set of evident XTdeficiencies (see Wilson, 2003, pp. 346-347). On the axiological realist meta-hypothesis, this allowed the (presumed) truth of Newton's force posit to be experientially concretized with respect to the previously troubling DRSEs. Herschel discovered Uranus, whose behavior likewise stood as a clear type (a) XTdeficiency, and Leverrier and Adams posited a trans-Uranian planet (see Herschel 1849, p. 668) to make the truths of Newton's force posit and other parts of the system such that those truths were experientially concretized in the DRSEs.

Einstein was mindful of what we can point to as a type (b) XT deficiency, where it is evident that there were DRSEs regarding the advancement of Mercury's perihelion for which he, at least, had no matching prediction statements. Taking an account of that advancement to be a pre-condition for a new theory of gravitation, Einstein eventually landed on the field equation of general relativity in 1915, and soon after that gave an approximate solution to the behavior of Mercury (Einstein 1915). Schwarzschild quickly followed up by offering an exact solution to the field equation that remedies that type (b) XT-deficiency (Schwarzschild 1916a, b). Doing so, the idea here is that he increased the experiential concretization of the (possible) truth of Einstein's field equation. ${ }^{11}$ With that solution he also provides an exact prediction 
regarding the so-called bending of light around massive objects. Strictly speaking, initially, and against that exact prediction, the (almost wholly forgotten) eclipse measurements of 1918 by Curtis and Campbell (see, Earman and Glymour 1980, pp. 65-66) stood as a type (a) XT-deficiency for Einstein's field equation (see my 2016b, p. 98). ${ }^{12}$ However, the well-known Eddington expedition took place in 1919 and the eclipse results were taken by Eddington to eliminate that (i.e., Curtis and Campbell's) type (a) XTdeficiency for Einstein's field equation. This last example is instructive for the sake of my illustration in that eighteen of the Sobral plates were rejected, those that, say, Curtis would have taken to confirm a Newtonian value. The hypotheses Eddington employed to reject them, despite (or even because of) the clear sky in Sobral, included the hypothesis that they were distorted by the heat. Two plates favored by Eddington, from Principe where the sky was cloudy, were taken to favor Einstein's theory (Earman and Glymour 1980, p. 74). We can understand this as an attempt to experientially concretize the truth of Einstein's field equation via very surface-level auxiliary hypotheses, including auxiliaries of the kind that make observations theory-laden. Assuming Einstein's field equation to be true, its truth was theoretically channeled down through the Schwarzschild solution to a specific prediction about the so-called bending of light and Eddington's auxiliaries in such a way that the consequence was claimed to match the DRSE's regarding the two plates Eddington emphasized in his report to the Royal Society. Stepping back to the choice between the two deep-level theories, it was claimed that the Newtonian system should be rejected in favor of the Einstein equation and its developing system. This emphatically hasty story is meant to illustrate (not secure the truth of) some of the primary but basic content of the axiological realist metahypothesis: that an IncXT, an increase in experientially concretized truth, is the end toward which changes in our theoretical systems are (systematically) directed—-be those changes deep theoretical changes, say on the nature of gravitation; or, complicated auxiliary modifications, such as those resulting from Laplace's perturbation theory; or more surface-level auxiliary statements invoked by Eddington, say his particular hypotheses about which plates are acceptable.

\section{Bridges: dimensions, virtues, and degree of implication}


Wanting now to elucidate relations between the empirical meta-hypothesis of systematicity theory and that of this axiological realist meta-hypothesis, I'll begin by noting a way in which systematicity theory is informative for at least the casual expression of the latter. First, we can understand the axiological realist meta-hypothesis offered in 3.1 to be a systematic articulation of the standard realist's (less than informative) posit that science seeks truth. Second, pre-systematicity theory, that casual expression is, as we've seen, that science seeks a specific subclass of true claims. However, recognizing that inquiry is a broad concept - which includes not only the positing of deep theories but also further theorizing to connect such theories to experience — and seeking to "activate the resources of systematicity theory" (203), there are two points at which we can bolster this casual expression of my axiological posit:

Science is marked by a systematic quest for truths of a certain subclass, namely, those that are systematically connected to documented reports of specific experiences, DRSEs.

As far as shorthand goes, I think this is informative: it already reveals a strong relation between the two meta-hypotheses.

Informative though such shorthand may be, further articulation of that relation invites us to consider what those meta-hypotheses require or promote in scientific theorizing. In 3.1, I noted that there are ten desiderata that are required of, or at least promoted by, the quest for an IncXT. One question is how the nine dimensions of systematicity—which Hoyningen-Huene concedes overlap with one another and constitute an incomplete list (37) — relate to at least some such virtues. Beyond his dimensions, Hoyningen-Huene grants that there is an "ensemble of scientific values pertinent to the respective scientific community," including “accuracy, consistency, scope, simplicity, and fruitfulness" (185, see also 93-94, 125). It has come to be generally accepted that such Kuhnian criteria are employed in theory choice. ${ }^{13}$ Hoyningen-Huene talks about the possible "intertranslatability of scientific values and degrees of systematicity" (205-206), and he takes it to be "plausible" that one system "outperforming its predecessor ...with respect to these values also has a higher overall degree of systematicity. .." (185). He even offers some broad-brush translations between his dimensions and these virtues (185-186). Given the 
necessary conditions for my posited goal and given the potential intertranslatability between the dimensions of systematicity theory and the generally accepted virtues, I suspect that inquiry into both could reveal a number of further solid bridges between the two meta-hypotheses. However, here I will identify another virtue that is not explicitly included on the standard list, and a desideratum that I do not take to be reducible to the others in my list of ten. To name that virtue in advance of my articulation of it below, I will call it “an increase in a system's degree of implication.”

Importantly for present purposes, I also suggest that this new virtue is a pivotal component of systematicity theory. Although sometimes Hoyningen-Huene appeals to this systematicity-relevant virtue only implicitly, there are many instances in which he emphasizes it rather explicitly, even if he does not name it. Also, I will show that it is strongly promoted by my axiological realist meta-hypothesis. That given, the following effort to explicitly identify and add this virtue to the standard list will provide a common ground for exploring relations between systematicity theory and my refined realist metahypothesis. It will also serve a number of other purposes. For instance, although it is not typically included in the Kuhnian list, this systematicity-relevant virtue clearly has a history of being discussed; and, accordingly, articulating it will help connect both meta-hypotheses here to some of the "older positions" that Hoyningen-Huene takes to be "special cases" (148) of systematicity theory. In fact, as with systematicity theory itself, I'd say this virtue dovetails, and its identification possibly unifies, many of those positions. Beyond clarifying the relation between axiological realism and systematicity theory, and in addition to introducing a further explicit theoretical virtue to the standard list, and possibly unifying the collection of positions, I expect that explicitly picking out this theoretical virtue-irrespective of its service as a bridge between axiological realism and systematicity theory-buttresses the empirical support for systematicity theory. It also suggests for systematicity theory a less tenuous unity, not only between the various domains of science $(29,169,209)$, but also between the nine dimensions (28) themselves. Or, put otherwise, although Hoyningen-Huene concedes that the notion of a degree of 
systematicity is "thin" (169), I expect that articulating this virtue will help us to see that it is just a bit thicker.

\subsection{Degree of implication}

The historical background of systematicity theory accords with that of the theoretical virtue I want to explicitly flag, that of increasing a system's degree of implication for a set of phenomena. The background for both begins with an emphasis on deduction. That said, the virtue we are after here is less than, we might say, deductive entailment. ${ }^{14}$ Notably I think, this virtue plays a central role in (one of) Peirce's articulation(s) of abduction (1958, p. 189), wherein an explanatory hypothesis makes that which it explains "a matter of course." Refining this notion, we integrate, first, the Duhemian thesis (overlooked by many, but discussed by Hoyningen-Huene on 96): in order to make claims that relate to our experiences, our theories must be connected to an entire, often very large, system of auxiliary hypotheses; combining that thesis with this Peircean virtue, the virtue must be understood in terms of hypotheses as conjoined to their system. Second, we must recognize that the degree to which such theory complexes imply various explananda can vary. Given these two points, this degree will be a function of not only a given hypothesis but also the particular auxiliary hypotheses to which it is conjoined in the system; and the degree to which a theoretical system implies an explanandum can be changed by modifying the auxiliaries, the result being a new system to be compared against its predecessor - even when modifications take place at, let's say, a surface level. For a general term denoting the degree to which an explanans implies its explananda, I will use degree of implication (in accord with my 2003). I will reserve this term for those relations that fall short of deductive entailment, i.e., short of 'implication' that is not measured in degree. So restricted, the greater the degree to which an explanans implies its explanandum, a DRSE or a set thereof, the more likely the latter is rendered by the former, and the greater is the explanans' degree of implication. And the idea is that modifications of a theoretical system that increase the degree to which a system implies DRSEs play a crucial role in science.

\subsection{Historical sketches for illustrating increases in a system's degree of implication}


I will now reinforce this idea by way of some historical sketches. Take Semmelweis's posit that cadaveric matter was the primary cause of the high mortality rate from puerperal fever in the First Maternity Division of the Vienna General Hospital (Semmelweis 1860; Hempel 1966; Lipton 2004; Tulodziecki 2013). Add some of the hypotheses summarizing DRSEs of which Semmelweis was mindful: for instance, that there were cases of puerperal fever in that same hospital's Second Maternity Division where deliveries were performed not by physicians coming from autopsies but by midwives who had no interaction with cadavers; that there were instances of puerperal fever outside of any hospital and away from any cadaveric matter, etc. Conjoin to these the hypothesis that the use of chlorinated lime solutions as disinfecting agents by physicians going from autopsies to the First Maternity Division sufficed to wholly eliminate the cadaveric matter from their hands. This mini-complex of hypotheses (along with others both supporting and conjoined) did not entail that puerperal fever would be eradicated from the First Maternity Division. However, when compared against its predecessor (sans Semmelweis's cadaveric matter posit), this mini-complex can be seen as increasing the degree of implication for a potential set of DRSEs pertaining to such a complete eradication. Later, Semmelweis's replacement of his posit in such a way that the broader notion of "putrid" replaced "cadaveric" — conjoined with, say, the broader application of chlorinated lime solutions - brings about an even greater increase in the system's degree of implication for such potential DRSEs.

Going back to the Presocratics, Anaximander is claimed to have said that "man came into being from an animal other than himself, namely the fish, which in early times he resembled."15 This claim implies a kind of "evolvability," something along the lines of "at least some species can change over time." Now take Empedocles hypothesis that "by pure chance ...many novelties sprang into being" (qtd. in Wheelwright, 135) conjoined to corollary hypotheses attributed to him that some life forms are able to function while others are not, so the latter, unable to reproduce, are eliminated. ${ }^{16}$ These Empedoclean hypotheses, let's call them, do not deductively entail Anaximander's hypothesis or its implication of evolvability. However, contrasting them against some other randomly selected set of statements, we see 
that they are at least informative with respect to Anaximander's, at least being suggestive of $a$ way by which the relevant changes could obtain. Although it may be that, even when contrasted against other random statements, we can attribute the Empedoclean hypotheses only a very low degree of implication for Anaximander's hypothesis, we can see that their degree of implication would be increased by, say, the posit that the novelties arising by pure chance were mutations that had bearing on - to use Lucretius's terms_- "propagation" and "progeny," etc.

Even when simply conjoined we would take the conjunction of Empedocles and Anaximander's hypothesis by themselves to have a very low degree of implication for any relevant DRSEs. However, in want of further illustrating the notion of increasing the degree of implication of a system, let's leap forward historically. Along with a massive collection of theoretical scaffolding and DRSEs from many areas of inquiry — including but not limited to nuclear physics, organic chemistry, molecular biology, plate-tectonic geology, zoology, paleontology —add a hypothesis that, say, from 400 to 390 million years ago all vertebrates were shoulder-head-conjoined water dwelling fish, and another hypothesis that approximately 385 million years ago some of these fish had bony fins, which facilitated their ability to move around in shallow fresh water. Now take another hypothesis that approximately 365 million years ago, there were tetrapods that lived on land, near fresh water, which, were more amphibian-like than fishlike, had shoulder/head separating necks, had eyes and nostrils on top of their flat heads, etc. Add to that the hypothesis that by Empedoclean mechanisms, suitably updated and detailed by our massive theory complex, these tetrapods were the ancestors of the bony-finned neckless fish. One can expect that, even beyond any DRSEs deductively entailed, we have now increased the degree of implication for many other DRSEs, for instance, the following: a set of fossils that would be dated at a time between 385 and 365 million years, say, 375 million years, ago; fossils of a species that, when compared to the bony-finned fish and the early tetrapods, has "pectoral appendages" with an intermediary skeletal structure, appendages that are "morphologically and functionally transitional between a fin and a limb" (Shubin et al. 2006, p. 764), which provide greater stance stability than the fish and less than that afforded by the limbs of early 
tetrapods. Relying on hypotheses regarding sedimentation and timelines expressed by geological strata, although no DRSEs regarding any observation are deductively entailed, our degree of implication for the desired DRSEs is increased significantly. That is, though the system is not related to them in a manner of strict deductive entailment, we've nonetheless increased our degree of implication for DRSEs regarding the "species of fossil sarcopterygian fish from the Late Devonian of Arctic Canada that represents an intermediate between fish with fins and tetrapods with limbs" (Daeschler et al. 2006, p. 757), namely the tetrapodomorph Tiktaalik roseae. (For more recent sets of relevant DRSEs regarding the pelvic girdle and fin, see NH. Shubin et al. 2014.) And going back to the start now, we can see that, by way of our current theoretical system, Empedocles and Anaximander's hypotheses also have a far greater degree of implication for DRSEs than they had before, for numerous DRSEs already in the corpus and others being introduced on an almost daily basis.

We can also have a quick look back at an example discussed earlier: Start high in the theoretical scaffolding with Einstein's field equation, which alone tells us nothing at all about specific human experiences (see my 2016b), so by itself has an extraordinarily low degree of implication for any DRSEs. Jump down to the Schwarzschild solution, which tells us something, at least far more than Einstein's equation, about the spacetime curvature and how it bears on light in our solar system; so it has a greater degree of implication than the Einstein equation, but tells us nothing about photographic plates. Jump down further (through our imagined deduction) to Eddington's surface-level hypotheses, which tell us just which of the photographic plates warrant our attention, so has a far greater degree of implication than the Schwarzschild solution, but tells us nothing about just what we will see on those plates. Although we are leaving out innumerably many other theoretical components between these theoretical pieces of the deductive system, with each of these jumps down the derivation, so to speak, we have a greater degree of implication for the relevant DRSEs, documented reports regarding specific experiences of, say, the careful measurements reported by Eddington that were made with respect to the two photographic plates he had selected. 


\subsection{The relevance of increasing a system's degree of implication in philosophy of science}

The idea in flagging this virtue is that, bracketing other factors, a system with a greater degree of implication for a set of phenomena is preferred over a system with a lower degree of implication for that same set, even when those phenomena are not entailed by either. Moving as we have to a notion that is considerably less demanding than the Peircean 'matter of course', and considering the examples above, we become mindful that degree of implication is relevant to, not only the domain of explanation, but to scientific inference itself. Take, for instance, the realist's appeal to inference to the best explanation, a form of inference whose intrinsic explanatory component allows us to see its connection to degree of implication rather naturally. Another inferential context in which at least the basic intuition contained in 'degree of implication' is addressed is that of specifying likelihood, the probability of evidence given a hypothesis. With the latter, the attention degree of implication has received tends to fall into the broader context of the attempt to attribute probability to hypotheses, which is usually treated as a measure of the strength of one's subjective belief. Bracketing epistemic realism as I am, and as I take Hoyningen-Huene to be — and going beyond the quibble that the term 'likelihood' is too easily conflated with 'likeliness' — it serves us to resist reducing degree of implication to a relation whose value lies in the service of belief. Moreover, it is important to note that the notion of likelihood, the probability of evidence given a hypothesis, is not identical to degree of implication, the degree to which documented reports of specific experiences are implied by a theoretical system. First, as just noted, the degree of implication pertains, not merely to a given hypothesis, but to a hypothesis as connected to a system; and increasing the degree of implication will very specifically involve adding to or modifying the theoretical system. Second, and most importantly, the concept of 'evidence' is a loaded one: evidence is evidence only in relation to something else (e.g. a hypothesis); yet documented reports of specific experiences may or may not qualify as evidence for (or, for that matter, against) a hypothesis and its theoretical system; and whether or not and the extent to which those DRSEs do qualify as standing in an evidential relation to a system is going to be contingent in part on the very measure at issue, the degree of implication, i.e. the degree to which 
they are implied by the system. For these reasons, we are well advised in the present context to avoid packing the notion of evidence into our conception of this property, and hence to refrain from using the more familiar term 'likelihood', which again means, the probability of evidence, given a hypothesis.

Although I take there to be a long history of recognizing the quest for a high degree of implication, even if it isn't made explicit, one may see it as notably absent in the Kuhnian virtues mentioned earlier. In fact, one might expect that Kuhn, who emphasized that large scale systems cannot be fully articulated, let alone, deductively articulated, would challenge my claim that increasing the degree of implication is at the heart of scientific inquiry. However, and despite the fact that my notion of increasing the degree of implication is not included in Kuhn's list of “virtues," I suggest that it is central to Kuhn's familiar notions of articulating a paradigm and solving puzzles.

I think that ultimately the point I've just made accords with Hoyningen-Huene's comments on Kuhn (164-165). But somewhat more importantly, I suggest that one sees something very similar to what I'm calling degree of implication alluded to, and nearly pin-pointed, throughout much of Hoyningen-Huene's presentation of systematicity theory. In fact, we can often take his use of "explanatory power" (63) (141) (157) as pointing to it; and even more tellingly, he emphasizes that in theorizing, we inquire, for instance, "whether the occurrence of A causally increases the probability of the occurrence of B" (99). While this virtue is not as isolated as I'm attempting to make it, Hoyningen-Huene implicitly and sometimes almost explicitly appeals to it in the course of discussing his dimensions. (For instance, in the context of descriptions (40), explanations $(61,63,67-68)$, predictions (87), the defense of knowledge claims (90, 94-95), epistemic connectedness $(118-120,121,123)$, the ideal of completeness $(125,126,130-133)$, and the generation of new knowledge $(133,140)$.) Irrespective of just how central it is to his text, here I bring this factor to the fore as a key component of the systematicity of scientific inquiry. As with Hoyningen-Huene's comments on the representation of knowledge, I'd say degree of implication is “independent enough . . . to constitute an autonomous dimension of systematicity" (142) and that it provides some unification "further interlocking different dimensions of systematicity" (142). Even if this 
virtue I'm making explicit is only what Hoyningen-Huene might call a kind, "a special case," of systematicity (154), it is unproblematic for our purposes that, as Hoyningen-Huene might put it, "systematicity covers more" (149). Whether it qualifies as its own dimension or not, my own suggestion is that — as with the interrelations he describes between the dimensions of representation and completeness — degree of implication "interlocks" (144) with other dimensions.

\subsection{Degree of implication and an IncXT; and comparative aspirational deductivism}

A proposal I am presently endorsing is that there is a strong relation between systematicity theory and my axiological scientific realism, and, in my view this theoretical virtue, increasing a system's degree of implication, is a domain in which the two intersect. With this theoretical virtue now specified, isolated, and illustrated by historical snapshots, along with my claim that it constitutes a central form of the systematicity of science, we can now consider the relation between degree of implication and the quest for an IncXT. In advance of doing so, a few clarifying points are in order. First, as in Sect. 3, for a statement to be experientially concretized as true, it must be such that prediction statements matching the documented reports of specific experience, DRSEs, can be logically deduced from the XT statement and its system. However, we also saw that a central component of the quest for an IncXT is the gradation to which an XT statement has specification toward, and is impacting on, DRSEs. This is where the degree to which an XT statement's truth is experientially concretized comes into play. Second, for at least non-zero values, neither of these measures - the degree to which an XT statement's truth is experientially concretized and the degree of implication - is here asserted as an absolute measure, i.e., such that it is to be attributed to a given hypothesis (or even system) non-comparatively. Rather, like every other measure of evaluation employed in our axiological hypothesis, these are evaluated only against competing systems, including a given system as it stood in advance of a modification. Third, although I will emphasize that concern with a system's degree of implication is intimately connected to the quest for experientially concretized truth, the two notions are not identical. As we are well aware, a system of wholly false statements, so one comprised of no XT statements, can make likely, or even entail DRSEs: a 
set of false explanans can very well have a high degree of implication for their explananda. A fourth point of clarification is that, because an IncXT can occur by, for instance, introducing a new XT statemente.g., one that has complete implication for a set of DRSEs, let's say—an IncXT can occur without changing the degree to which any particular XT statement is experientially concretized. Hence, the goal of bringing about an IncXT cannot be said to require, of a given choice between theory complexes, an increase in any particular XT statement's degree of implication. (This point is distinct from one for which I will soon argue, that increasing an XT statement's degree of experiential concretization requires an increase in the system's degree of implication). In contrast then with some of the ten desiderata listed at the end of 3.1, an increase in the system's degree of implication is not a necessary condition for an IncXT.

Nevertheless, we can discern, in the ways spelled out below, a strong relation between the two notions, namely: The quest for an IncXT encourages and so promotes the endeavor to increase the system's degree of implication, even if it doesn't require it. First, since the experiential concretization of truth lies at the heart of our axiological postulate, and since it is part of the nature of a goal to direct our attention to future changes in the system that might result in what we seek, we can see that, given the goal, a greater degree of experiential concretization, and hence, a greater degree of implication, for truths is valued. That is, we have implicit and forward looking grounds for valuing an increase in a system's degree of implication for those DRSEs in which truths in the system - including those experientially concretized in other DRSEs - are not yet experientially concretized. In short, increasing the degree of implication brings truths, insofar as there are truths in the system, closer toward experiential concretization. (This is importantly distinct from the notion of bringing individual hypotheses closer to the truth.)

Going beyond the fact that, with an eye toward future modifications, the goal implicitly leads us to value a high degree of implication, second, and more tellingly, the specifics of the axiological postulate explicitly promote increasing the degree of implication. Taking 'degree of experiential concretization' to reference the gradation to which an XT statement impacts, has specification toward, a set of DRSEs, and taking degree of implication as the degree to which a system of statements makes an explanandum likely, 
the following is clear: when an XT statement is not yet fully experientially concretized, but, say, an auxiliary modification has served to increase its degree of implication for a set of DRSEs, that modification suffices to increase the degree to which that XT statement's truth is experientially concretized. Moreover, for such DRSEs outside of those in which an XT statement is genuinely experientially concretized, increasing the experiential concretization of that XT statement in such DRSEs requires increasing its degree of implication. Although, again, the general goal, that of bringing about an increase in experientially concretized truth, does not entail/require an increase in degree of implication, that general goal explicitly includes increasing the degree of experiential concretization of XT statements. And we now see that increasing the degree of implication of XT statements is not only sufficient but also necessary for increasing the degree to which their truth is experientially concretized.

Because the quest for an IncXT strongly promotes the practice of increasing the degree of implication for these non-entailed reports documenting specific experiences, the quest for an IncXT is informative with regard to, explains, and justifies that practice. Expressed another way: independently of whether, descriptively, my axiological postulate captures a key component of inquiry, we can see that my postulate itself has a high degree of implication for the claim that central to inquiry is the (systematic) endeavor to increase the degree of implication of our theoretical system.

Thus far in this subsection we have been focusing on the evaluation and selection of theoretical options in place: the quest for an IncXT, promotes comparative preference for systems that meet, not only the ten virtues listed at the end of 3.1, but also promotes a preference for those that constitute an increase in the degree of implication. While all this pertains to system/theory/auxiliary choice, part of the potency of an axiological postulate lies in the fact that goals can prompt actions beyond mere choices. For instance, goals - ends toward which we direct our theorizing — can prompt the development of theoretical posits that make good candidates for later choice. I will now make clear one way in which the postulate that science seeks an IncXT is methodologically informative with regard to, not only evaluation and choice, 
but to theory/auxiliary development, or the act of theorizing itself, at the many varied levels in the system at which theorizing takes place.

Our axiology posits as a primary end toward which theorizing is directed the increase in truths that are, not derived from, but derived to reports regarding specific experiences. Expressing this in active terms, inquiry exemplified (e.g. science) is characterized by the endeavor to, not only posit truths, but to deductively push those truths through the theory complexes to DRSEs. And as above, this deductive pushing of truths can be done by the modification of the auxiliary scaffolding. Hence the quest for an IncXT, which includes this quest to push truths to experience, prompts inquirers - be they theorists, experimenters, data gatherers, etc.- - to actively modify auxiliaries in such a way as to increase the system's degree of implication. In want of a name for this dynamic endeavor of modifying auxiliaries to increase a system's degree of implication, we can dub it comparative aspirational deductivism. The claim here is not that deductive relations between theories and DRSEs are required or always attained, but only that empirical theorizing aspires to comparatively greater approximation toward deduction. Further, just as I am not claiming that my axiological postulate requires the endeavor to increase the degree of implication, I am not claiming that it entails this methodology. Rather, in accord with what I've noted above, my claim is that my axiological posit itself strongly promotes, has a high degree of implication for, comparative aspirational deductivism. Nonetheless, insofar as this methodology for theorizing —at every level—is employed in inquiry, my axiology both explains and justifies it.

To summarize and take stock of these various conceptions and the relations between them, at the heart of all this is the axiological postulate that, in choosing between theoretical systems, science seeks an IncXT; and the quest for an IncXT promotes a methodological factor in such choices, namely choosing those systems that have a greater degree of implication. Going beyond choice, the axiological posit promotes a related but distinguishable methodology for theorizing, one whose immediate aim is to bring about a greater degree of implication; to this component of methodology pertaining to theory/auxiliary development we have given the name comparative aspirational deductivism. My axiological postulate 
puts this methodology — the modification of auxiliaries so that a system's degree of implication is increased-at the heart of scientific inquiry.

Again, it is my view that there is a strong connection here with systematicity theory. The notion of comparative aspirational deductivism involves centrally what Hoyningen-Huene points to when discussing the "identification of causally relevant factors" (98), including those that are "yet unnoticed" (101). And it captures "the creative work needed to derive consequences" from theoretical constructs (95). Hoyningen-Huene points out that systematicity's ideal of completeness "requires systematically identifying missing pieces," and is "one of sciences most important driving forces" (132). I suggest that aspirational deductivism affords the most systematic way for such identification. Hoyningen-Huene notes that "in the sciences, one cannot always realize the desirable degree of systematicity." (34) However, the "ideal of completeness evaluates positively those contributions to this system that move it into the direction of completeness" (126), making the system less "spotty and selective" (140). Comparative aspirational deductivism is, I suggest, methodologically pivotal to a foundational form - perhaps even its own dimension — of systematicity.

Hoyningen-Huene concedes that it is difficult to say "how the different dimensions of systematicity should be weighed" (179). However, I suggest that the ranking for increasing the degree of implication and for comparative aspirational deductivism is high, up there with their related virtues of breadth of scope, explanatory depth, etc. In fact, it is worth considering, not only whether, as I've claimed, the quest to increase the degree of implication is a fundamental dimension of the systematicity in science, but more broadly whether the quest for that virtue — though not reducible to any of those Kuhnian virtues — ties into all of systematicity's dimensions. Minimally, at least, I suggest that, like systematicity more broadly, consideration of the importance of the quest for a high degree of implication and of comparative aspirational deductivism allows us to do as Hoyningen-Huene seeks to do: to "organize many existing insights about science ...and gain new ones" (20). 
In light of these considerations, I'll close this section with a slightly more refined snapshot of why I am not concerned with a demarcation criterion. There will no doubt be variance in the degree to which theoretical systems conform to the necessary conditions of, and other ends promoted by, a goal of inquiry — such as experientially concretized truth. And the content of the corpus at a given stage of inquiry will afford greater potential for stronger answers to some questions than other questions have. However, criteria such as empirical accuracy, breadth of scope, degree of implication, etc., allow adjudication between competing products of inquiry, both in terms of what is accepted and what has promise. (In part, because of a constituent's dependence on the theoretical scaffolding, the degree of implication will often be what differentiates competing answers to a given question. But that degree will also differentiate questions themselves: some will, at a given stage of inquiry, lack any candidate answers with a high degree of implication.) It is for reasons such as these that I do not see a demarcation criterion as any kind of precondition for a rich conception of inquiry. The problem is no worse for inquiry whose questions take us outside those of the "physical sciences" (but within "Wissenschaft" or "science" in Hoyningen-Huene's broad sense.)

\section{Comparative evaluation of the two empirical meta-hypotheses}

We've seen above that the endeavor to bring about an IncXT promotes, in theory choice, increasing a statement's degree of implication, and it promotes comparative aspirational deductivism as a methodology for theorizing. At the same time, I am suggesting that these two practices promoted by the quest for an IncXT constitute key instantiations of systematicity. Minimally, then, by explicating these virtues, we've uncovered what I take to be strong bridge between the meta-hypothesis of systematicity theory and the meta-hypothesis of Socratic scientific realism proposed in Sect. 3. With this bridge articulated, we can now more explicitly embark on a comparative evaluation of our two meta-hypotheses.

In Sect. 2, prior to introducing my own meta-hypothesis, I ended up landing on the question, what does the scientific enterprise systematically seek? There I was at least implicitly inquiring about how systematicity theory fares as an axiological meta-hypothesis. Although we saw that Hoyningen-Huene 
resists an explicit appeal to goals for the purpose of identifying a demarcation criterion, I expect I've now made clear that he discusses goals rather unflinchingly. In fact, I'd say it has become apparent that the dimensions of systematicity themselves can be understood as goals. Moreover, in the course of discussing goals explicitly, Hoyningen-Huene offers important axiological insights, for instance, that some goals can be understood as promoting others: even beyond mere "overlap," they are sometimes "strongly connected" (36) to one another. An example he gives is that, in some instances, completeness "may not be a goal in itself but a means in order to promote another dimension" (130). And he discusses instances in which it "primarily served other dimensions" (130), such as the defense of theoretical content ("knowledge claims"). More generally, he talks about "traits" that promote systematicity (33). And "some means [that are] enhancing the systematicity in one dimension are also instrumental in increasing the systematicity in another dimension" (146). With the recognition that some goals can promote others, and for the purposes of comparing our meta-hypotheses, allow me to now explicitly suppose that systematicity theory's empirical meta-hypothesis is, ultimately, axiological. In basic form, where we left it in Sect. 2, that meta-hypothesis is something along the lines of "scientific inquiry systematically seeks a corpus of ideas." (Note that without any appeal to theoretical truth this meta-hypothesis would accord with, and I'd say fall under the domain of, non-realist axiologies such as those encouraged by van Fraassen and Laudan.) With our two empirical axiological meta-hypotheses about the nature of scientific inquiry in hand, we are in need of meta-criteria for adjudicating between them.

\subsection{Criteria for meta-hypotheses regarding the nature of inquiry}

Accepting that our meta-hypotheses about the nature of inquiry are themselves tools for inquiry and seeking meta-criteria for adjudicating between empirical meta-hypotheses, we can say the following, in short: The more one meta-hypothesis purporting to describe inquiry lives up to the identifiable demands its description requires, the better it fares. And in terms of comparison, if one among two competing meta-hypotheses fares better on shared identifiable criteria — or for an even stronger case, if it fares better on both its own and the other's identifiable criteria - then that meta-hypothesis is preferable. These meta- 
criteria accord well with Hoyningen-Huene's endeavors to systematically articulate a way of understanding science itself. Offering a "description" of "a set of phenomena" (38) that is as systematic as possible, his own project aspires to achieve what it describes: he wants the "content" of systematicity theory to be "consistent with its own way of proceeding" (34); being itself "systematically organized," systematicity theory "intends to exhibit itself what its subject matter is" (208). Likewise, with my axiological realist meta-hypothesis.

In Sect. 4, I discussed the quest in science for a high degree of implication and ultimately, what I've called, comparative aspirational deductivism. That exploration suggests that both meta-hypotheses describe as central to scientific inquiry comparisons of what we would call, in an explanatory context, explanatory power. Conjoining the centrality of that to the posit that empirical meta-hypotheses purporting to describe the goal of scientific inquiry should live up to the identifiable demands of the goal they describe, we can inquire as to whether one of those meta-hypotheses serves to explain the other. This requires consideration of how explanatory relations can obtain between axiologies. And for this, to the axiological insight we've seen just above — that some goals can promote other goals — we can append the following: in cases in which one goal promotes another, the empirical hypothesis that the one goal is pursued can explain the empirical hypothesis that the other is pursued. Hoyningen-Huene concurs with this second insight in the following way: "if a descriptive analysis of science reveals something about the factual cognitive goals of science and some tendencies of how these goals are pursued, we may better understand why some candidate goals are [taken to be] more desirable than others" (33). Here Hoyningen-Huene is allowing for an "external" explanation as to why increased systematicity is central to science. Acknowledging the meta-criteria above - e.g. that axiological hypotheses live up to the identifiable demands of the goal they describe — and recognizing the way in which one axiological metahypothesis can explain another, my proposal, hinted at throughout this text, is that my axiological realist meta-hypothesis explains the axiological meta-hypothesis of systematicity theory. Or, we can say, the 
quest for an increase in experientially concretized truth explains (at least much of) the systematicity of science.

Toward substantiating that proposal, it will be recalled that there are two core parts of my axiological meta-hypothesis. One specifies truth as the goal of science; the other, my refinement of the standard realist meta-hypothesis, specifies the type of truth that is sought. With regard to the first, HoyningenHuene notes that, on his account, truth "does come into play"; but in his view, it does so "only implicitly in dimension 4, the defense of knowledge claims" (173). However, here in want of supporting the standard realist axiological hypothesis (so the first part of my version), I push the demand for a systematic explanation of the phenomena of systematic inquiry. Consider the systematicity involved in "institutionalized critical discourse" (109). One would not be content to say that critical discourse takes place simply for the sake of itself, or even simply for the sake of being systematic. Rather, my proposal is that it is done in the service of another end, the other end promoting it, namely the quest for increasing the true theoretical constituents in a theory complex. Likewise consider what Hoyningen-Huene calls “organized skepticism" (110). That skepticism has a purpose, and I suggest it is to push our theory complexes forward in want of increasing the truths therein. (It will be noticed that although my axiological hypothesis pertains explicitly to theoretical systems, we are seeing here and below that it explains, so ultimately pertains to, much more than mere theories.)

Of course, as I've emphasized, according to my own axiological meta-hypothesis, it is not simply the quest for truth per se that explains these dimensions of systematic inquiry. Rather, it is the quest for an increase in experientially concretized truth. And for that more specific axiological realist meta-hypothesis we have already seen an explanatory argument. I've proposed that the quest for a high degree of implication and the related but distinct comparative aspirational deductivism are not only part of science but at the core of its systematicity. Additionally, I argued in 4.4 that the quest for an increase in experientially concretized truth promotes and so explains this core kind of systematicity. Meanwhile insofar as that core is itself simply a kind of systematicity, systematicity theory it seems only describes it 
without clearly explaining it. Going further, note that there is nothing about the demand for systematicity by itself that requires that our systematically attained corpus of ideas connects to reports of our experience. Merely requiring systematicity at least appears to allow a "pie in the sky," or detached, or vacuous but nonetheless systematic theory complex. Similarly consider the hypothesis that contributions from one discipline are "systematically imported and utilized" (140) by another, or that the sciences are "extremely systematic in their efforts" to generate and "collect data" (139). On the latter, it may be that, "systematically increasing the energy of accelerators means systematically increasing the range of available data about particles" (137), and so the second goal explains the first. But what explanation have we for increasing the range, or breadth of scope, of available data at all? Add to these features of scientific inquiry the "scientific aim of testing some scientific hypothesis" (11). I propose that it would be patently uninformative to hypothesize the following: the scientific enterprise embarks on these tasks only for the sake of systematically importing contributions, systematically generating and collecting data, about say particles, and using those data to systematically test scientific hypotheses. Or, if one finds oneself thinking it would not be uninformative, one is bringing in an implicit presupposition that my axiological meta-hypothesis attempts to explicate. ${ }^{17}$

Notably these points strike at the standard realist hypothesis as well: the quest for mere truth, without greater axiological specification of a subset of true claims, fails to explain-for instance, fails to have much of any degree of implication for- empirical accuracy or breadth of scope, etc. The latter is especially troublesome given that increasing breadth of scope decreases the logical probability that the theoretical system is true. The natural hypothesis is that contributions are imported, data are generated and collected, and theory complexes are tested against those data with the goal of increasing the experientially concretized truth in our system. And just in case a set of hypotheses is systematically tested and a prediction confirmed, and just in case one or more theories or auxiliary hypotheses connected to that prediction are also true, that confirmation will constitute an instance in which those truths are experientially concretized. While standard axiological realism is uninformative with regard to such 
criteria, my axiological realist meta-hypothesis endeavors to explain why such virtues are a part of science. It is the quest for not merely truth but for increasing the experientially concretized truths of theory complexes in science.

We can now take stock to emphasize that, although my axiological meta-hypothesis is primarily expressed in terms of theorizing, the set of features of the scientific enterprise it pertains to, explains, and is informative with respect to is vastly greater than the subset we call "scientific theories." First, I've emphasized theoretical systems throughout and at various points have referenced surface-level theorizing and the theory-laden nature of "observations." The idea is that, irrespective of how "theory-thin" certain statements may appear, as long as they are statements that go beyond, even if they are 'wrapped around', DRSEs, their introduction into a system, or into our general theoretical corpus, nonetheless constitutes theorizing — which I propose is directed toward increasing the experiential concretization of truths. Second, although both truth and the experiential concretization of truths ultimately constitute properties of statements, the many varied practices of the scientific enterprise can be explained and justified by the quest for an increase in experientially concretized truth. Consider, for instance, the various expeditions mentioned earlier - to measure the shape of the earth, to find "an intermediate between fish with fins and tetrapods with limbs," to photograph an eclipse_or Eddington's discarding of plates, or the activities just noted of "building ever larger accelerators" and working to attain "higher collision energies" (137).

Although these are practices — often such as to be traced back to physical activities—what I am positing is the end toward which they and indefinitely many elements of the scientific enterprise are directed, that of increasing true statements in the system, experientially concretizing those new truths, and experientially concretizing true statements already present in the system.

Finally, going beyond the explanatory relations between axiological meta-hypotheses, I submit that a meta-hypothesis that provides an axiological explanation of another can stand in a justificatory relation to the other. That is, a goal or end that requires or promotes another value can justify that value. Here again, I suggest that Hoyningen-Huene agrees: "if ...our analysis reveals in which sense and why the sciences 
have in fact a strong tendency in the direction of increased systematicity, we may conclude that the benefits of increased systematicity are desirable" (33). I propose that my axiological realist metahypothesis, not only explains the quest for systematicity in science, but also that it is informative with respect to the desirability of increasing systematicity, and more fundamentally that it justifies that endeavor to increase systematicity. Put another way, posited as the end toward which scientific inquiry is directed, the quest for an increase in experientially concretized truth (as detailed in Sect. 3) justifies, and I suggest is needed to justify, the systematicity of scientific inquiry. [The challenge of primary goal justification is addressed in my (2011, Section 7).]

\subsection{Implicit axiological realism?}

Finally, however, I want to suggest, what might now be somewhat surprising, that systematicity theory nearly allows for, and in fact occasionally hints at, something along the lines of my axiological realist meta-hypothesis, provided we are permitted to include pieces of systematicity theory to show that my axiological hypothesis does not take us so far beyond some of those pieces. On Hoyningen-Huene's view, central to inquiry is not only the avoidance of errors or false posits, but also their elimination, even if, originally, they had been in a weak sense systematically attained $(87,89,109) .{ }^{18}$ In addition to the importance of confronting "theoretical constructs with empirical data" (94), he explicitly discusses the elimination of falsity in the context of the importance of precision (104); and it amounts to a key component of his fourth dimension of systematicity, the defense of theoretical constituents ("knowledge claims") that are at least candidates for acceptance. Hoyningen-Huene writes, "error avoidance" is a key component of the nature of scientific inquiry (198); "in our context, namely, science, the concept of error elimination comes with a highly positive value connotation" (198). Science "appears to be the human enterprise that is most systematic in its attempt to eliminate error in the search for knowledge" (89). Science systematically seeks both to avoid accepting falsity and to eliminate falsity that had previously been accepted. Since replacing one false constituent with another false constituent would not eliminate that falsity, we ask, what is the alternative property of constituents that is sought? And here the natural 
suggestion is that the quest to replace falsity boils down to the quest for truth. In fact, both of these quests - seeking to avoid falsity and to eliminate it — can be understood in terms of my specific axiological posit: to return to the language of Sect. 3, the first is included in the quest to "avoid increasing the non-XT statements" of a (newly accepted) system; and the second is included in the quest to replace false posits with XT statements, and more generally, to "remedy evident XT deficiencies."

Moreover, I suggest that systematicity theory has as its own goal a true description of "what science is up to" (91). And insofar as Hoyningen-Huene wants the "content" of systematicity theory to be "consistent with its own way of proceeding" (34), he has reason to posit truth as an aim of inquiry more generally. Hoyningen-Huene suggests that older on the nature of science views were likely "at least, in some sense, approximately right" and likely had "stability" and "some degree of persuasiveness" because they were "getting something about the contemporary science right" (149). And "his own way of proceeding" (34) amounts to offering "a theoretical representation aiming at an accurate description of scientific inquiry" (12). I would translate the notions of "something right" and "an accurate description" as a true description — and I would add, one whose truth is experientially concretized.

\section{Concluding remarks}

Accepting that the sciences systematically seek to replace falsity, that systematicity theory itself seeks truth, and that systematicity theory shares its goal with science, we are led to the meta-hypothesis that central to scientific inquiry is the quest to replace falsity with truth. Adding that the virtue of a high degree of implication and the method of comparative aspirational deductivism are forms of systematicity that can be explained by my axiological realist meta-hypothesis, and allowing as relevant HoyningenHuene's emphasis on the idea that science generates and collects data, we are now at least approximating my specific empirical axiological realist meta-hypothesis. With the latter only a small step from, if not already implicitly embraced within, systematicity theory, I suggest that, given the explanatory and justificatory promise of my axiological meta-hypothesis, the next—I dare say necessary— “step toward completeness" for systematicity theory is to embrace axiological realism explicitly. In other words, I am 
arguing that in order for systematicity theory to live up to its own demands, it needs to be conjoined to (something along the lines of) my axiological realist meta-hypothesis. Using insights of systematicity theory to clarify the shorthand of that meta-hypothesis, we have the following: in the choice between theory complexes, the scientific enterprise systematically seeks to increase experientially concretized truths, to increase those truths that are systematically connected to our documented reports of experience. (See Sect. 3 for the detailed meta-hypothesis.) Embracing the idea that the quest for an increase in experientially concretized truth is "operative by influencing" (126) scientific "theory decisions" (125), and mindful of a shared quest for completeness, I invite systematic consideration and empirical testing of my axiological realist meta-hypothesis as not merely an informative supplement to, but even, as I've argued, a needed explanation of, and justification for, systematicity theory. To the quick question, what is it that the scientific enterprise is systematically doing, in the course of systematically predicting, explaining, etc.? My quick answer — on behalf of Socratic scientific realism—is that the scientific enterprise is systematically seeking to increase, in its theoretical systems, experientially concretized truth.

\section{Footnotes}

1. Take even the practices categorized as "representation." Beyond constituting a kind of inquiry themselves, I suggest that they are wholly central to systematic inquiry in general. The development of nomenclature and taxonomy, for instance, are informative with respect to, and help scientists track, interrelations that obtain between parts of our theoretical corpus. And it's not merely that representations afford a better understanding of, and lead to new discoveries regarding, that corpus; they often direct us toward new information about the world. HoyningenHuene explicitly includes the periodic table in this context (see 143-144 and footnotes on 248), and one need only consider the successful predictions derived even from Mendeleev's version (see my 2002).

2. Also, Hoyningen-Huene discusses "everyday knowledge" and "commonsense knowledge" without hesitation (for instance, ix, 8, 14, 37, 40, 102, 113, 124, 133, 141, 158, 164, 180, 209). 
And because "everyday knowledge" is the central contrast in his thesis statement, along with his assertions to the effect that science "directly contradicts common sense [i.e. everyday] knowledge" (191), he is clearly not employing the traditional definition of "knowledge."

3. He similarly avoids any temptation "to assume or imply" the "definitive absence of truth" (21), which, rather than suggesting he is a realist, accords unproblematically with anti-realisms of the kind offered by van Fraassen and Laudan.

4. At the end of Sect. 4, I will collect my own reasons for setting aside worries about a demarcation criterion.

5. By the end of Sect. 5, I will hope to have made clear why I take my own meta-hypothesis to live up to this desideratum.

6. For instance, he references "certain cognitive goals" (29), discusses "the quest for higher generality of theories" (127), and how the sciences "go about realizing their goal of science completion" (133). He notes that "certain norms can be identified that are relevant in scientific communities" (110).

7. "The social norms and ...institutions" of scientific communities "must be conducive to the exertion of the cognitive norms that must be operative for the enterprise to reach its institutional goal. In the present perspective, this goal comprises the maintenance and even increase of the systematicity of scientific knowledge in various dimensions" (109). An example of that: "It is obvious that sciences that seek empirical generalizations, possibly of quantitative form, thereby increase the degree of systematicity in comparison to other kinds of knowledge" (49). More on connecting goals to one another in Sect. 5 below.

8. Here, in accord with Hoyningen-Huene's own points that we need not equate talk of values with talk of "intentions" (quoted next), I have deliberately left out the clause "Scientists want to explore ..." 
9. In light of these phrases (see also his comment in my footnote 7 above), one may be surprised to see that, even on his own view, it "does not work" (243) to say science seeks "the systematic generation of knowledge that makes a difference" (Börner 2010, p. 53). However, HoyningenHuene's concerns are quite different from those I'm expressing. They pertain, not to "knowledge," but to axiology as a demarcation criterion: "it is not good enough to distinguish science from other knowledge-seeking enterprises ...." (242).

10. This postulate is articulated in more detail in my (2005) and (2011). Since it is meant to be an articulation of the end toward which scientific inquiry is directed, its content is not meant to be surprising. Rather, its novelty lies in the fact that achieving that goal requires and promotes certain theoretical virtues whose relation to one another and especially to truth are otherwise unclear.

11. As I argue in my (2016a) some of the auxiliaries introduced by Schwarzschild were blatantly false and not accepted into the system; on the axiological realist view, these were used as tools for the experiential concretization of the field equation's (presumed) truth, along with that of other auxiliaries in the background of Schwarzschild's solution.

12. Their data rather seemed to serve the experiential concretization of (what the Newtonians treated as) the truth of Newton's posit conjoined to the posit that light corpuscles have mass.

13. See, for instance, Kuhn (1977), Thagard (1978), McMullin (1996), Lipton (2004), et al. See also my (2005). In fact, as Hoyningen-Huene points out, Okasha $(2011,84)$ takes the Kuhnian thesis that there are such criteria to be "widely accepted in the philosophy of science" (244, footnote to 125).

14. In another context, namely, discussing the relation between descriptive and normative claims, Hoyningen-Huene hints at a kind of "implication" that falls short of entailment (33). 
15. Hippolytus, quoted in Wheelwright, ed. (1966, p. 58). Neglecting interpretive concerns, here I entertain Wheelwright's take that Anaximander "had proposed the general hypothesis that the human race had somehow evolved from lower forms, in particular from marine animals" (1966, p. 125).

16. With explicit reference to Empedocles, Aristotle entertains the possibility that useful features arising in nature - "the front teeth sharp, fitted for tearing, the molars broad and useful for grinding down the food"-were "merely a coincidental result"; "and so with all other parts" in nature, "such things survived, being organized spontaneously in a fitting way; whereas those which grew otherwise perished and continue to perish" (198b25-32, 1984, p. 339). Later Lucretius wrote, "there perished many a stock, unable by propagation to forge a progeny" (1916, p. 222).

17. Below I will consider this second possibility, that what my meta-hypothesis makes explicit may be implicit in systematicity theory.

18. Although error may seem to be a broader concept than falsity, one that includes for instance fallacious reasoning (that might nonetheless employ and even arrive at true claims), I posit here that falsity still lies at bottom of such errors; for instance, it is false that such reasoning is valid or, less formally, legitimate.

\section{Notes}

\section{Acknowledgements}

Research for this paper was supported by the AHRC (Grant No. AH/L011646/1), UK, Grant: Contemporary Scientific Realism and the History of Science. I thank three anonymous referees along with Hasok Chang, Bschir Karim, and Simon Lohse for their very helpful feedback. Thanks also to Joe Breidenstein. This paper is dedicated to my friend and former graduate student Adam Hayden, his wife, Whitney, and their children. 


\section{References}

1. Aristotle. (1984). In J. Barnes (Ed.), Complete works of Aristotle (Vol. 1). Revised Oxford translation. Princeton: Princeton University Press.

2. Börner, K. (2010). Atlas of science: Visualizing what we know. Cambridge: MIT Press.

3. Daeschler, E., Shubin, N., \& Jenkins, F. (2006). A Devonian tetrapod-like fish and the evolution of the tetrapod body plan. Nature, 440, 757-763.

4. Earman, J., \& Glymour, C. (1980). Relativity and eclipses: The British eclipse expeditions of 1919 and their predecessors. Historical Studies in the Physical Sciences, 11, 49-85.

5. Einstein, A. (1915). Explanation of the perihelion motion of Mercury from the general theory of relativity. In The collected papers of Albert Einstein, Doc. 24. Volume 6: The Berlin years: Writings, 1914-1917 (pp. 112-116). (English translation supplement, translation by Brian Doyle)

6. Hempel, C. (1966). The philosophy of natural science. Englewood Cliffs: Prentice Hall.

7. Herschel, J. (1849). Outlines of astronomy, 1869 (10th ed.). London: P. F. Collier and Son.

8. Hoare, M. (2005). The quest for the true figure of the earth: Ideas and expeditions in four centuries of geodesy, science, technology and culture, 1700-1945. Aldershot: Ashgate.

9. Hoyningen-Huene, P. (2014). Systematicity: The nature of science. Oxford: Oxford University Press.

10. Kuhn, T. (1977). Objectivity, value judgment, and theory choice. In T.S. Kuhn (Ed.), The essential tension (pp. 320-39). Chicago: University of Chicago Press.

11. Lipton, P. (2004). Inference to the best explanation. London: Routledge.

12. Lucretius. (1916). On the nature of things (Vol. 5) (W. E. Leonard Trans.). New York: EP Dutton and Co. 
13. Lyons, T. D. (2002). Scientific realism and the pessimistic meta-modus tollens. In S. Clarke \& T. D. Lyons (Eds.), Recent themes in the philosophy of science: Scientific realism and commonsense (pp. 63-90). Dordrecht: Springer.

14. Lyons, T. D. (2003). Explaining the success of a scientific theory. Philosophy of Science, 70(5), 891-901.

15. Lyons, T. D. (2005). Toward a purely axiological scientific realism. Erkenntnis, 63(2), 167-204.

16. Lyons, T. D. (2006). Scientific realism and the stratagema de divide et impera. British Journal for the Philosophy of Science, 57(3), 537-560.

17. Lyons, T. D. (2009). Non-competitor conditions in the scientific realism debate. International Studies in the Philosophy of Science, 23(1), 65-84.

18. Lyons, T. D. (2011). The problem of deep competitors and the pursuit of unknowable truths. Journal for General Philosophy of Science, 42(2), 317-338.

19. Lyons, T. D. (2014). The historically informed modus ponens against scientific realism: Articulation, critique, and restoration. International Studies in Philosophy of Science, 27(4), 369392.

20. Lyons, T. D. (2015). Scientific realism. In P. Humphries (Ed.), Oxford handbook of philosophy of science. New York: Oxford University Press. doi: 10.1093/oxfordhb/9780199368815.013.30.

21. Lyons, T. D. (2016a). Selectivity, historical testability, and the non-epistemic tenets of scientific realism. Synthese,. doi: 10.1007/s11229-016-1103-3.

22. Lyons, T. D. (2016b). Structural realism versus deployment realism: A comparative evaluation. Studies in History and Philosophy of Science, 59, 95-105. 
23. Main, R. (1860). Address delivered by the president on presenting the gold medal of the society Professor Hansen. In Monthly notices of the royal astronomical society, volumes 19-21; volumes 1858-1861 (Vol. XX, no. 4).

24. McMullin, E. (1996). Epistemic virtue and theory appraisal. In I. Douven \& L. Horsten (Eds.), Realism in the sciences: Proceedings of the Ernan McMullin symposium, Leuven, 1995 (pp. 1334). Leuven: Leuven University Press.

25. Okasha, S. (2011). Theory choice and social choice: Kuhn versus Arrow. Mind, 120(477), 83115.

26. Peirce, Charles S. (1958). Collected papers (Vol. 5). Cambridge: Harvard University Press.

27. Rescher, N. (1982). Empirical inquiry. London: Athlone Press.

28. Schwarzschild, K. (1916a). On the gravitational field of a point-mass, according to Einstein's theory (Larissa Borissova and Dmitri Rabounski (2008) Trans.). The Abraham Zelmanov Journal: The Journal for General Relativity, Gravitation and Cosmology, 1, 10-19.

29. Schwarzschild, K. (1916b). On the gravitational field of a sphere of incompressible liquid, according to Einstein's theory (Larissa Borissova and Dmitri Rabounski (2008) Trans.). The Abraham Zelmanov Journal: The Journal for General Relativity, Gravitation and Cosmology, 1, 20-32.

30. Semmelweis, I. (1860). Etiology, concept and prophylaxis of childbed fever (K.C. Carter Trans.). Madison: University of Wisconsin Press, 1983.

31. Shubin, N., Daeschler, E., \& Jenkins, F. (2006). The pectoral fin of Tiktaalik roseae and the origin of the tetrapod limb. Nature, 440, 764-771.

32. Shubin, N., Daeschler, E., \& Jenkins, F. (2014). Pelvic girdle and fin of Tiktaalik roseae. Proceedings of the National Academy of Sciences, 111, 893-899. 
33. Thagard, P. (1978). The best explanation: Criteria for theory choice. Journal of Philosophy, 75, $76-92$.

34. Tulodziecki, D. (2013). Shattering the myth of Semmelweis. Philosophy of Science, 80, 10651075.

35. Vickers, P. (2013). A confrontation of convergent realism. Philosophy of Science, 80, 189-211.

36. Wheelwright, P. (Ed.). (1966). The presocratics. New York: Macmillan.

37. Wilson, C. (2003). Astronomy and cosmology. In R. Porter (Ed.), The Cambridge history of science: Eighteenth-century science Vol. 4. (pp. 328-353). Cambridge: Cambridge University Press. 